\title{
Control of the Handedness of Self-assemblies of Dipeptides by the Chirality of Phenylalanine and Steric Hindrance of Phenylglycine
}

Shuwei Lin, Yi Li, Baozong Li, and Yonggang Yang*

Jiangsu Key Laboratory of Advanced Functional Polymer Design and Application, Department of Polymer Science and Engineering, State and Local Joint Engineering Laboratory for Novel Functional Polymeric Materials, College of Chemistry, Chemical Engineering and Materials Science, Soochow University, Suzhou 215123, P.R. China.

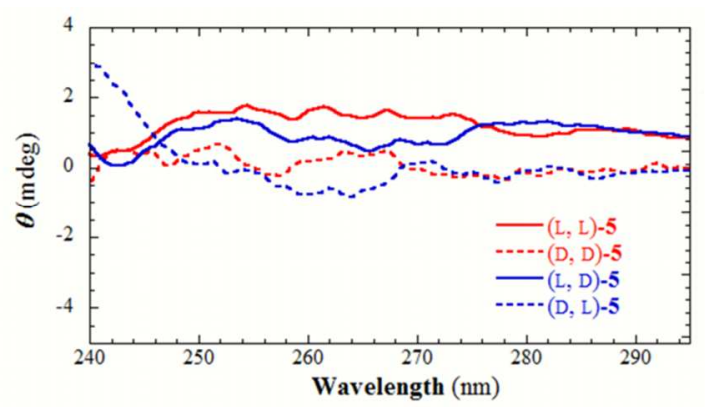

Figure S1. CD spectra of 5 at the longer wavelength. 

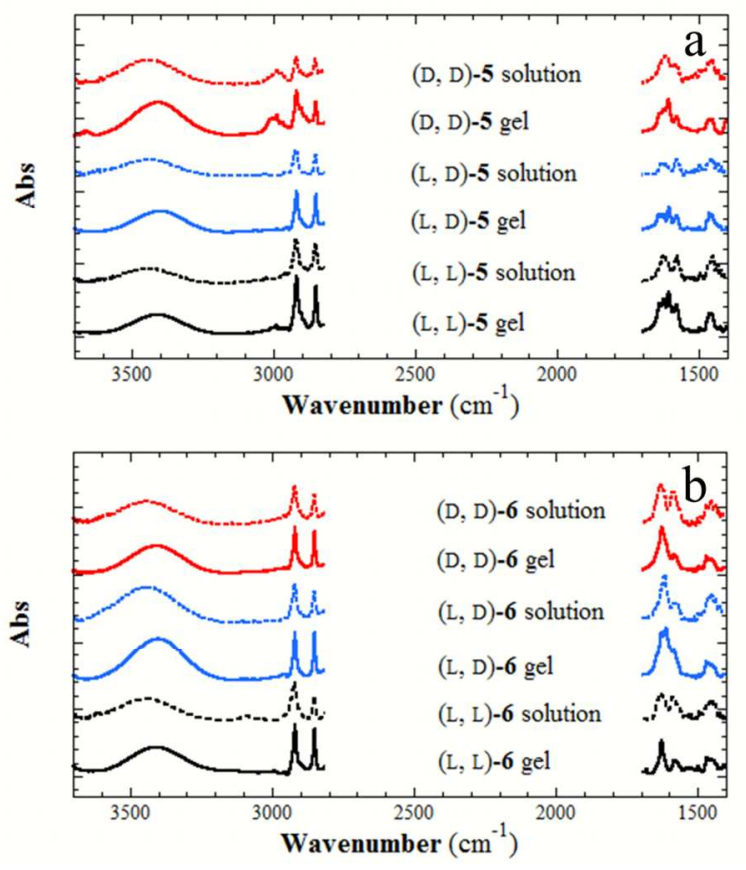

Figure S2. FT-IR spectra of the hydrogels and solutions of the dipeptides in $\mathrm{D}_{2} \mathrm{O}$ at a concentration of $15 \mathrm{~g} \mathrm{~L}^{-1}$. (a) 5 and (b) 6 . 

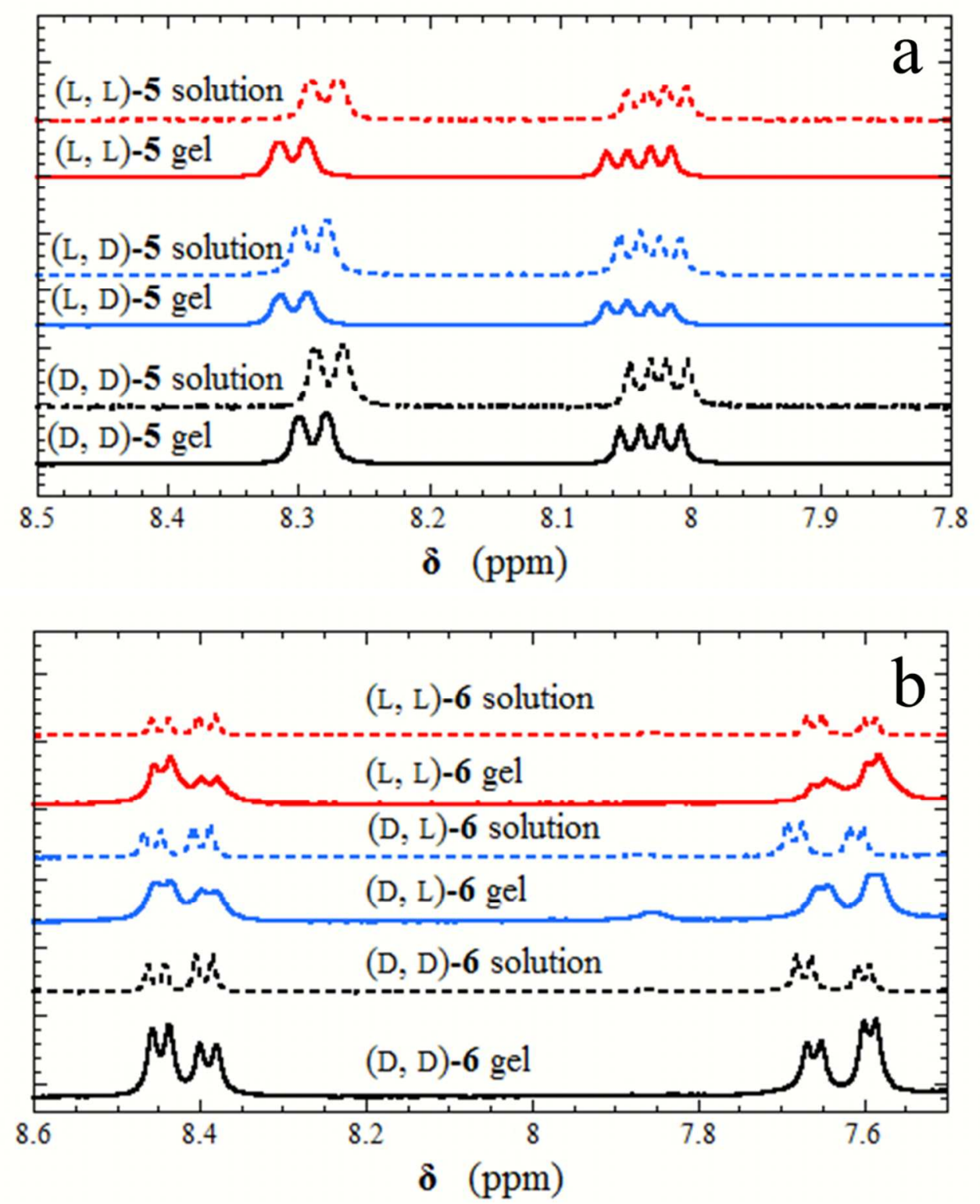

Figure S3. ${ }^{1} \mathrm{H}$ NMR spectra of the gels $\left(15 \mathrm{~g} \mathrm{~L}^{-1}\right)$ and solutions $\left(5 \mathrm{~g} \mathrm{~L}^{-1}\right)$ of the dipeptides in DMSO- $d_{6}$. (a) 5 and (b) 6. 